\title{
Predicting Domestic Homicides and Serious Violence in Dorset: a Replication of Thornton's Thames Valley Analysis
}

\author{
Robert Chalkley $^{1} \cdot$ Heather Strang ${ }^{2}$
}

Published online: 3 August 2017

(C) The Author(s) 2017. This article is an open access publication

\begin{abstract}
Research Question What facts known to police, if any, could have predicted the 107 domestic and family murders and near-murders in Dorset (UK) police area over a recent 7-year period, using methods identical to Thornton's $(2011,2017)$ ?

Data The data were gathered from all 107 cases of domestic murders, manslaughter, attempted murder or grievous bodily harm with intent in Dorset between April 2009 and March 2015, plus a matched control sample of 214 arrestees for less-deadly violent offences.

Methods Replicating Thornton's Thames Valley analysis, two methods were used: (1) calculating errors in predictions from previous risk assessments using the UK's DASH (Domestic Abuse, Stalking and Harassment) risk assessment protocol and (2) making a case-control comparison of Thornton's risk factors between the deadly domestic violence cases in Dorset to a Dorset sample of victims and offenders in all violence cases during the same time period.

Findings False negative risk assessments were found in $67 \%$ of the deadly violence cases with prior police contact (45 of 67) not classified by DASH as 'high risk.' The false positives in the same time period totalled 12,279 cases of no serious harm among 12,301 cases receiving high risk assessments, for a $99 \%$ false positive rate. Possible alternative predictors were found in differences between deadly offenders and controls, both male and female, although it is not known whether these variables were added to the records before or after the deadly violence event. Male offenders in deadly violence cases were $120 \%$ more likely to have their police records note a self-harm warning, $20 \%$ more likely to have a suicide warning, yet only half as likely to have a mental health warning as control males. Female offenders in deadly violence cases were
\end{abstract}

Heather Strang

hs404@cam.ac.uk

1 Dorset Police, Dorset, UK

2 University of Cambridge, Cambridge, UK 
$355 \%$ more likely to have a weapons warning on file, $244 \%$ more likely to have a mental health warning and $146 \%$ more likely to have a drugs warning than female control case offenders.

Conclusions The current risk assessment tool (DASH) failed to predict the majority of deadly domestic violence cases over 6 years in Dorset. Other factors could do better, but more research is required before highly accurate forecasting tools can be applied to help save the lives of more domestic abuse victims.

Keywords Domestic homicide · Prediction - DASH - Case-control · Suicide threats · Self-harm

\section{Introduction}

The accuracy of prediction of completed and attempted domestic homicides in Britain was first examined by Thornton $(2011,2017)$. Her core findings were that most such cases occur without any prior contact with police, that when risk assessments have been done they are almost always incorrect and that a case-control study found that a marker for attempted suicide by the offender may be the best predictor available. These findings are important, yet like all science, they require replication of research methods to assess their generalisability.

A central question in Thornton's analysis was the accuracy of DASH, the most widely-used risk assessment tool for UK domestic violence cases. In order to predict those who are most at risk of highest harm, UK police generally complete a domestic abuse (DA) risk assessment at every response they make to domestic incidents. This risk assessment focuses on previous occurrences of abuse. Yet the premise of this focus is that police have already had contact with victims of most serious DA before potentially deadly violence occurs. That premise has been challenged by Thornton's (2011) analysis of deadly domestic violence in Thames Valley Police, as well as other studies showing most deadly cases had no prior police contact (Sherman and Strang 1996; Sherman et al. 1990).

This study replicates Thornton's analytic approach as closely as possible, clarifying how many victims of serious domestic assaults in Dorset had previously sought help from police and how well the risk assessment was able to predict the subsequent harm. It also replicates Thornton's case-control analysis to identify any risk factors which may assist in improving our ability to predict deadly domestic violence.

In the study period of 2009-2015, Dorset police officers attending a DA incident were required to carry out an 'initial assessment of the risk faced' by the victim by completing the DASH (Domestic Abuse, Stalking and Harassment) risk assessment tool (HMIC 2014b, p. 15). DASH was implemented as part of a national program in 2009. Having completed the assessment by interviewing the victim, officers were required to grade the risk level of each case as standard, medium or high risk, depending on the overall score. Cases considered high risk were referred to the Multi Agency Risk Assessment Conference (MARAC). The MARAC provided an opportunity for both statutory and voluntary agencies to regularly meet to share information on such high risk cases so that action could be taken to safeguard those most at risk (Dorset County Council 2015). 
In 2013, UK Police underwent a national inspection of the capability to manage DA. The inspection by Her Majesty's Inspectorate of Constabulary concluded that the 'response to victims of DA is not good enough' (HMIC 2014a, p. 6) and specifically recommended the risk assessment process 'be made more efficient' (HMIC 2014a, p. 22).

This study provides a further basis in evidence for improving risk assessment nationally, examining the most recent cases of deadly domestic violence. Between 2009 and 2015 within Dorset, domestic abuse resulted in 11 murders, 12 attempted murders, one manslaughter and 83 cases of grievous bodily harm with intent. These cases form the basis for three research questions:

1. How many cases of serious domestic assault and murder in Dorset had a prior history of reporting domestic abuse?

2. How accurate was DASH based on prior history in terms of false positive and false negative predictions?

3. Can a case-control study produce more accurate risk indicators than DASH?

\section{Data and Methods}

The methodology employed throughout this study replicates Sara Thornton's methods in her Cambridge Master's thesis (Thornton 2011, 2017). The following details the method adopted in order to examine each of the research questions.

The Dorset Police crime recording system, known as the Criminal Intelligence System (CIS), was interrogated to identify all cases of murder, attempted murder, manslaughter and grievous bodily harm with intent, which carried a marker flag for DA. These cases constitute the numerator. The cases captured fell within the date range of 1 April 2009, the approximate date of DASH implementation, to 31 March 2015, and is therefore the widest possible date range from which to maximise the available data collated.

In determining which cases to include, serious but non-lethal DA reports were also submitted. These cases were considered 'near misses', where it was more by luck than intention that a fatal injury was not inflicted, as outlined by Campbell (1995, p. 29) who stated 'whether or not a serious assault becomes a homicide may be determined by the speed and/or quality of emergency response.' Including these additional cases also increases the case numbers from 11 murders within Dorset to a total number of 107 eligible cases, which substantially increases the statistical power of any analysis.

In selecting these cases, the UK Government Home Office DA definition (Home Office 2013) was applied. Of the 107 eligible cases, 72 (67\%) victims were female and $35(33 \%)$ were male, with those in an intimate partner relationship numbering $91(85 \%)$ and the remainder within the wider family setting. We can readily acknowledge obvious challenges when considering both intimate partner and family members together, but it will make the findings more directly comparable to Thornton (2011) and other studies.

Each of the 107 victims were then scrutinised for any prior contact with Dorset Police since 1 January 2002. This was the time limit used by Thornton (2011) as it would allow for a minimum of a generous 7 years between possible reports. It is also 
likely that some victims would not have previously reported DA - the challenge of under-reporting such crimes is well known.

The 107 eligible cases were then studied to see if those with prior contact with Dorset Police regarding DA had been subject to a previous DASH risk assessment and, if so, what their most recent risk assessment grading was.

In order to examine the false positive rate, the Dorset Police CIS was further probed for all DASH risk assessments graded as high risk within Dorset during the same time frame between 1 April 2009 and 31 March 2015, resulting in 12,301 identified cases. These were then compared to the 107 cases of serious and fatal domestic assaults already highlighted, to clarify how many of these high risk cases did not go on to be seriously or fatally assaulted.

Finally, this study drew a case-control sample, undertaking an important process not completed during the development of DASH. The focus of this study, as in Thornton's (2011), is how likely these factors are to appear in the cases and control groups, by first considering the incidence rates in both. In the view of Schlesselman and Stolley (1982), analysis of these incidence rates identifies the ratio between them, producing $R$, where $R>1$ is a positive association and $R<1$ a negative. The purpose of case-control studies is not to highlight incidence rates, but to provide clarity on the relative risk between the groups under scrutiny, as case and control groups are chosen from the same overall population. Monahan and Steadman (2003) explained that in determining relevant rates, it is best to divide the known cases by the overall population. As such, the prevalence rate of lethal or serious domestic assault in Dorset over 6 years was 107 cases divided by 6 producing an average of 17.6 per year. This is further divided by the Dorset population of 754,500 to produce a rate of 2.34 per 100,000 people per year. By comparison, Thornton (2011) identified a prevalence rate in the Thames Valley area of 1.78 per 100,000 per year, revealing that the deadly DA rate is about one-third higher in Dorset.

To identify the Thames Valley case-control samples, Thornton (2011) noted that only a minority of victims of serious or fatal domestic assaults had a previous DA report $(45 \%)$ in the Thames Valley area. She concluded that victims were not considered suitable as the optimal group for the study, so that the offender group were employed as a broader cohort for the case-control comparison. Of note, in Dorset, $63 \%$ (67/107) of the victims were identified as having reported previous DA, which is a clear majority and differs from the findings of Thornton (2011). Yet to replicate her methods, this study used offenders as the optimal group. To identify the most appropriate comparison group of offenders, Table 1 shows the Dorset offenders' histories, with the results of Thornton (2011) in brackets for comparison.

Table 1 identifies 'prior arrest' and 'prior criminal record' as having the highest prevalence in the offender case group, which was also the case within the Thames Valley area. Since Farrington et al. (2006) found that $40 \%$ of English men have criminal records by the age of 50 , merely using criminal records as a selection criterion risks a large cohort with the potential of increased false positives. Due to these concerns, Thornton (2011) used 'prior arrest for violence' as the key matching criterion for deadly domestic violence. This study's sampling framework for the control group was confirmed as all offenders arrested for violence during the same time frame from 1 April 2009 to 31 March 2015 in Dorset. That sampling frame identified 27,870 offenders who matched the above criteria. 
Table 1 Offenders' criminal histories

\begin{tabular}{lll}
\hline Previous criminal record & $\begin{array}{l}\text { Dorset number } \\
\text { (Thames Valley number) }\end{array}$ & $\begin{array}{l}\text { Dorset \% of cases } \\
\text { (Thames Valley \%) }\end{array}$ \\
\hline Offender has prior criminal record & $87(83)$ & $82.1(69.1) \%$ \\
Offender has prior criminal record for violence & $58(58)$ & $54.7(48.3) \%$ \\
Offender has prior arrest & $90(92)$ & $84.9(76.6) \%$ \\
Offender has prior arrest for violence & $83(71)$ & $78.3(59.1) \%$ \\
Offender has no prior criminal record & $15(37)$ & $14.1(30.8) \%$ \\
Total & $107(120)$ & $100 \%$ \\
\hline
\end{tabular}

In order to more closely match the control and deadly violence cases, Thornton (2011, p. 49) selected gender and age as the most theoretically relevant case characteristics. In her study as in this one, control samples were randomly selected from an age-range quota sample and arranged into male and female blocks. To achieve the required power of analysis, twice the number of control samples was necessary, compared to the cases (Lewallen and Courtright 1998). To ensure this, the number of cases within the female control sample was set at 58, to be compared against the 29 female case offenders, with the male sample set at 156, to be compared against the 78 male cases.

Having identified the final female case and control cohorts, this study collected Police National Computer data to test for exposure to selected risk factors. The final stage of the analysis process tests the results of the bivariate analyses of the ratio of risk factors for significant differences. A series of $t$ tests for independent samples will be applied to the case and control samples with reference to the first eight of the above variables, which consider offending history. Cohen's $D$ (standardised mean difference) will be then employed to measure any effect size. The remaining seven variables, relating to the exposure of PNC warning markers, will be evaluated by way of the relative risk ratio process described previously.

\section{Findings}

Descriptive Analysis Table 2 shows that 107 offences of murder, attempted murder, manslaughter and grievous bodily harm with intent were reported to Dorset Police between 1 April 2009 and 31 March 2015. These reports included 33\% male and 67\%

Table 2 Gender and outcomes in Dorset

\begin{tabular}{llllll}
\hline & Murder & Attempt murder & Manslaughter & GBH W/I & All offences \\
\hline Female victims & $8(73 \%)$ & $10(83 \%)$ & $1(100 \%)$ & $53(64 \%)$ & $72(67 \%)$ \\
Male victims & $3(27 \%)$ & $2(17 \%)$ & $0(0 \%)$ & $30(36 \%)$ & $35(33 \%)$ \\
Total & $11(100 \%)$ & $12(100 \%)$ & $1(100 \%)$ & $83(100 \%)$ & $107(100 \%)$ \\
\hline
\end{tabular}


female victims, all aged 16 and over, including both intimate partners and family members.

Of the 107 Dorset cases, 91 were offences between intimate partners, with just 16 between family members. The geographical spread of the cases can be better understood when comparing the rural/urban divide. The urban areas of Bournemouth, Poole, and Weymouth and Portland provides a value of 3.35 cases per 100,000 population per year, compared to a value of 1.28 for the remainder of the county, revealing a 2.6 times higher rate in the urban areas.

Deadly Domestic Assault and Prior Victim History of Reporting DA Of the 107 cases, 67 had previously contacted Dorset police for a domestic incident (63\%). This is much higher than the $45 \%$ found by Thornton (2011). Of the 35 total male victims, $23(66 \%)$ had prior DA contact with Police, as did 44 of the 72 female victims $(61 \%)$. These prior contact rates are also higher than those identified within the Thames Valley area, with Thornton finding male and female rates of 46 and $42 \%$, respectively.

Thornton (2011) undertook further analysis of the crime type of the most recent previous police contact by the victims. Within Dorset, Table 3 shows low harm, minor and non-crime domestic incidents as the majority of prior cases, with verbal altercations accounting for 21 of the 67 cases $(31.3 \%)$, followed by ABH and common assault with $16(23.9 \%)$ and $13(19.4 \%)$, respectively. A prior grievous bodily harm with intent was found in only one case. This is very similar to the patterns identified by Thornton (2011) in the Thames Valley area.

Analysing the prior contacts by deadly outcome revealed that 8 out of the 11 domestic murder victims $(73 \%)$ in Dorset had no prior contact with police. In addition, where the victims had made prior contact with police regarding previous domestic assaults, $31 \%$ had only 1 or 2 prior contacts (Table 4 ). When combined, of the 107 cases, 61 ( $57 \%$ of all cases) had between 0 and 2 prior contacts with police regarding DA.

Table 3 Most recent prior victim contact with the police for domestic incidents

\begin{tabular}{lll}
\hline $\begin{array}{l}\text { Victim's most recent prior domestic } \\
\text { incident contact with the police }\end{array}$ & Number & $\%$ of sample \\
\hline $\begin{array}{l}\text { Non-crime domestic incident } \\
\quad \text { verbal altercation) }\end{array}$ & 21 & $31.3 \%$ \\
ABH & 16 & $23.9 \%$ \\
Common assault & 13 & $19.4 \%$ \\
Harassment & 5 & $7.4 \%$ \\
Breach of injunction & 4 & $6.0 \%$ \\
Public order/breach of the peace & 3 & $4.5 \%$ \\
Criminal damage & 2 & $3.0 \%$ \\
Theft & 1 & $1.5 \%$ \\
GBH & 1 & $1.5 \%$ \\
Sexual assault (minor) & 1 & $1.5 \%$ \\
Total & 67 & $100 \%$ \\
\hline
\end{tabular}


Table 4 Prior incident contacts between victim and Dorset police

\begin{tabular}{lll}
\hline $\begin{array}{l}\text { Total number } \\
\text { of contacts }\end{array}$ & $\begin{array}{l}\text { Number } \\
\text { of victims }\end{array}$ & Cumulative \% \\
\hline $20+$ & 3 & 3 \\
$10-19$ & 10 & 12 \\
$3-9$ & 33 & 43 \\
2 & 8 & 50 \\
1 & 13 & 63 \\
Sub-total & 67 & 63 \\
No prior DA contact & 40 & 37 \\
$\quad$ with police & 107 & 100 \\
Total & & \\
\hline
\end{tabular}

Accuracy of DASH Risk Assessments The victims with prior contact regarding DA were examined for any previous DASH risk assessment and, if so, with what risk grading. All 67 cases with prior police contact produced a risk assessment, of which 22 were classified as high risk, 16 as medium and 29 as standard. The false negative rate was then calculated by dividing the number of cases that were not assessed as high risk (therefore not considered for MARAC safeguarding measures) by the total number of cases where there was both prior contact and a risk assessment completed. This represents 45 of the 67 cases, revealing an overall false negative rate of $67 \%$.

More specifically, only 3 of the 11 domestic murder victims in Dorset had previous DA contact with Police. When considering those cases, only one of the three had been previously risk assessed as high, the other two had been risk assessed as standard, again providing a $67 \%$ false negative rate. Additionally, when considering attempted murder, 3 of the 5 cases had not been graded high risk, providing a false negative rate of $60 \%$. The victims of Grievous Bodily Harm with intent, with prior contact, had not been graded high risk in 40 of the 59 cases, a $69 \%$ false negative rate. The single case of manslaughter did not have prior contact with police. Within the Thames Valley area, Thornton $(2011,2017)$ had also identified high levels of no prior contact and false negative rate, 55 and $90 \%$ respectively.

In seeking to clarify the false-positive rate within Dorset, all high risk assessments conducted over the same date range were collated and compared to the cases of serious and fatal domestic assaults already highlighted. Having done so, 12,301 high risk assessments were recorded over the period of April 2009 to March 2015, with only 22 later resulting in a serious or fatal domestic assault. This equates to a false positive rate of greater than $99 \%$. It is important to note that this rate could be misleading and indicative of safeguarding measures put in place as a result of the high risk grading and exposure to the MARAC process.

Case-Control Analysis To assess the comparability of the control sample with the case offenders, initial analysis was undertaken to clarify whether any difference existed between the case and control offenders in terms of prior violent offending. In doing so, offenders in both groups with no prior convictions and cautions for violent offences were identified and compared, with no significant differences between the 107 deadly violence offenders and their case-controls (Chalkley 2015). 
Male Block The male offenders involved in serious or fatal DA and the sample of male offenders from the wider risk population of those arrested for all Home Office violent offences, were then compared, in terms of exposure to the alternative risk factors identified by Thornton (2011). Table 5 shows that deadly violence offenders are either no different from case-controls or show less frequent prior crime and older ages of first arrest and conviction.

Table 6 shows that among the variables examined well after the deadly violence, the largest difference between the male deadly violence offenders and their male case-controls was in the former's $120 \%$ higher prevalence of 'threats of self-harm other than suicide' than among control offenders. While, like Thornton, we do not know when this notation was entered onto the offenders' Police National Computer (PNC) record, it remains possible that some or most of them had this record noted prior to their deadly act of domestic abuse. Suicide markers were also more prevalent (by 17\%) among the deadly males compared to their controls, although far less than the $223 \%$ higher prevalence of suicide markers among the deadly violence offenders in the Thames Valley case-control analysis (Thornton 2011, 2017). This finding seems inconsistent, however, with the $50 \%$ lower rate of mental health markers among the deadly males than their controls.

Female Offenders Block The female offenders in serious and fatal DA in Dorset were compared with female offenders from the wider risk population of those arrested for violence for differences between these two groups in risk factors examined in Thornton $(2011,2017)$. Like the deadly male offenders, deadly female offenders generally had less frequent criminality and older ages of onset for arrest and conviction than the control cases (Table 7). Table 8 shows that the largest difference between the two groups is in a PNC warning for weapons, with the deadly female offenders $355 \%$ more likely than female control cases to have

Table 5 Male case-control analysis: frequency values

\begin{tabular}{|c|c|c|c|c|}
\hline & $\begin{array}{l}\text { Deadly male offenders } \\
\text { in the Dorset cases, } \\
N=78\end{array}$ & $\begin{array}{l}\text { Male offenders in the } \\
\text { Dorset control sample, } \\
N=156\end{array}$ & $\begin{array}{l}\text { Effect size } \\
\text { Cohen's } D\end{array}$ & $\begin{array}{l}P \text { value } \\
\text { of } t \text { test }\end{array}$ \\
\hline Average number of prior arrests & 11.96 & 16.70 & 0.211 & 0.167 \\
\hline $\begin{array}{l}\text { Average number of prior arrests } \\
\text { for violence }\end{array}$ & 4.65 & 6.56 & 0.277 & 0.061 \\
\hline $\begin{array}{l}\text { Average number of prior } \\
\text { convictions and cautions }\end{array}$ & 18.23 & 17.79 & 0.016 & 0.916 \\
\hline $\begin{array}{l}\text { Average number of prior } \\
\text { convictions and cautions } \\
\text { for violence }\end{array}$ & 3.74 & 5.26 & 0.251 & 0.091 \\
\hline Average age at first arrest & 23.17 & 21.74 & 0.118 & 0.370 \\
\hline $\begin{array}{l}\text { Average age at first arrest for } \\
\text { violence }\end{array}$ & 27.90 & 23.91 & 0.317 & 0.016 \\
\hline Average age at first conviction & 22.41 & 20.01 & 0.236 & 0.094 \\
\hline $\begin{array}{l}\text { Average age at first conviction } \\
\text { for violence }\end{array}$ & 27.38 & 22.20 & 0.455 & 0.002 \\
\hline
\end{tabular}


Table 6 Male case-control analysis: relative risk ratios

\begin{tabular}{llll}
\hline & $\begin{array}{l}\text { Deadly male offenders } \\
\text { in the Dorset cases, } \\
N=78\end{array}$ & $\begin{array}{l}\text { Male offenders in the } \\
\text { Dorset control sample, } \\
N=156\end{array}$ & $\begin{array}{l}\text { Relative } \\
\text { risk ratio }\end{array}$ \\
\hline Unemployed & $42.3 \%$ & $43.6 \%$ & 0.970 \\
PNC warning for weapons & $17.9 \%$ & $15.4 \%$ & 1.162 \\
PNC warning for firearms & $1.3 \%$ & $1.3 \%$ & 1.000 \\
PNC warning for drugs & $23.1 \%$ & $17.9 \%$ & 1.290 \\
PNC warning for self-Harm—other & $14.1 \%$ & $6.4 \%$ & 2.203 \\
$\quad$ than suicide & $7.7 \%$ & $6.4 \%$ & 1.203 \\
PNC warning for suicidal risk & $5.1 \%$ & $9.6 \%$ & 0.531 \\
\hline PNC warning for mental health & & & \\
\hline
\end{tabular}

such a marker on their records. This finding is almost identical to Thornton's (2011, 2017) finding that in Thames Valley, deadly female offenders had 365\% higher prevalence of weapons markers than female controls. While these findings may be entirely due to notations made after the occurrence of deadly domestic violence, it is also possible that they were entered prior to the deadly case and could therefore have contributed to a prediction of high risk of committing a deadly domestic assault.

Table 8 also shows that, unlike the males, the female deadly offenders also had much higher prevalence ( $244 \%$ more) of mental health issues marked on their police records than the controls and $146 \%$ higher prevalence of drug use issues.

Table 7 Female case-control-frequency variables

\begin{tabular}{lllll}
\hline & $\begin{array}{l}\text { Deadly female offenders in } \\
\text { the Dorset cases } \\
N=29\end{array}$ & $\begin{array}{l}\text { Female offenders in } \\
\text { the Dorset control } \\
\text { sample } N=58\end{array}$ & $\begin{array}{l}\text { Effect size } \\
\text { Cohen's } D\end{array}$ & $\begin{array}{c}P \text { value } \\
\text { of } t \text { test }\end{array}$ \\
\hline $\begin{array}{l}\text { Average number of prior arrests } \\
\text { Average number of prior arrests } \\
\text { for violence }\end{array}$ & 7.86 & 9.12 & -0.089 & 0.702 \\
$\begin{array}{l}\text { Average number of prior } \\
\text { convictions and cautions }\end{array}$ & 12.97 & 5.09 & -0.322 & 0.195 \\
$\begin{array}{l}\text { Average number of prior } \\
\text { convictions and cautions for } \\
\text { violence }\end{array}$ & 2.66 & 5.58 & 0.395 & 0.046 \\
$\begin{array}{l}\text { Average age at first arrest } \\
\text { Average age at first arrest }\end{array}$ & 27.96 & 3.46 & -0.111 & 0.640 \\
$\quad$ for violence & 31.73 & & & \\
$\begin{array}{l}\text { Average age at first conviction } \\
\text { Average age at first conviction } \\
\text { for violence }\end{array}$ & 26.57 & 26.11 & 0.159 & 0.499 \\
\hline
\end{tabular}


Table 8 Female case-control-relative risk ratios

\begin{tabular}{lccc}
\hline & $\begin{array}{l}\text { Deadly female offenders } \\
\text { in the Dorset cases }\end{array}$ & $\begin{array}{l}\text { Offenders in the } \\
\text { case-control sample }\end{array}$ & $\begin{array}{l}\text { Relative } \\
\text { risk ratio }\end{array}$ \\
\hline Unemployed & $62.1 \%$ & $70.9 \%$ & 0.87 \\
PNC warning for weapons & $24.1 \%$ & $5.3 \%$ & 4.55 \\
PNC warning for firearms & $0 \%$ & $0 \%$ & 0 \\
$\begin{array}{l}\text { PNC warning for drugs_describes } \\
\text { a loose association controlled drugs }\end{array}$ & $17.2 \%$ & $7.0 \%$ & 2.46 \\
PNC warning for self-harm—other & $13.8 \%$ & $15.8 \%$ & 0.87 \\
$\quad$ & & $8.8 \%$ & \\
than suicide & $10.3 \%$ & $7.0 \%$ & 3.17 \\
PNC warning for suicidal & $24.1 \%$ & & 3.44 \\
\hline
\end{tabular}

\section{Conclusion}

It is clear from these findings that the accuracy of domestic abuse risk assessment based on DASH is extremely low, especially on the critical dimension of false negatives. As employed with Dorset cases, it would fail to predict most of the actual cases of deadly domestic violence on the last prior police contact as 'high risk.' It is therefore supportive of the College of Policing (2015) review of DA policy, which advised police forces to continue using their current risk assessment methods 'in the immediate term' and encourages forces that do not employ DASH to 'feel comfortable with their current arrangements'.

Whether other tools than DASH can predict with any greater accuracy remains to be seen. The results of this study of Dorset data are similar in nature to those presented by Thornton (2011) in Thames Valley. Yet differences in results did exist leading to factors identified which could be considered specific to each force area, indicating local differences in offender history and behaviour. These slight differences suggest a need for each force to make more use of its own data to help inform on risk management at a local level and to become less reliant on a national risk assessment developed from London-based cases. This view, combined with concerns regarding the lack of confidence in front-line officers making best use of a structured professional judgement based tool such as DASH, supports the need for such a different approach in protecting those most at risk of serious harm. This approach could lead to bespoke risk assessments using local data to protect local victims.

When policies of vital importance, such as those guiding our response to domestic abuse, are to be reviewed and considered by the newly formed National Police Chiefs Council (formerly ACPO), the closer relationship policing now enjoys with both academia and the College of Policing will be of huge benefit. This relationship must be maintained to ensure research is undertaken in partnership, with effective evaluations and a clear focus on taking an evidence-based approach, an approach not employed during the development of DASH. 
Acknowledgements This study is an independent contribution to professional scholarship and does not necessarily represent the views of the authors' employers or funders. The authors wish to thank the College of Policing and the Dorset Police for supporting this research through their joint funding of the first author's enrolment in the Cambridge University Master's course in applied criminology and police management, known as the Cambridge Police Executive Programme, where he completed this study as a master's thesis. The first author also wishes to thank Daniel Thompson, Alistair James and Julie Hankin of Dorset Police for many hours laboriously mining PNC records.

Inspector Robert Chalkley M.St. (Cantab) of Dorset Police is the area commander for North Dorset, leading for five neighbourhood policing teams.

Professor Heather Strang Ph.D. (A.N.U.) is the Director of the Cambridge Police Executive Programme and served as the thesis supervisor for this study. She is also the Director of Research at the Jerry Lee Centre for Experimental Criminology in the Institute of Criminology, University of Cambridge.

Open Access This article is distributed under the terms of the Creative Commons Attribution 4.0 International License (http://creativecommons.org/licenses/by/4.0/), which permits unrestricted use, distribution, and reproduction in any medium, provided you give appropriate credit to the original author(s) and the source, provide a link to the Creative Commons license, and indicate if changes were made.

\section{References}

Bland, M. (2014). Targeting escalation in common domestic abuse: how much, if any? (Master's dissertation, University of Cambridge).

Campbell, J. (1995). Prediction of homicide of and by battered women. In J. C. Campbell (Ed.), Assessing dangerousness: violence by sexual offenders, batterers and child abusers. London: Sage.

Campbell, J., Webster, D., \& Glass, N. (2009). The danger assessment: validation of a lethality risk assessment instrument for intimate partner femicide. Journal of Interpersonal Violence, 24(4), 653-674.

Chalkley, R. (2015). Predicting serious domestic assaults and murder in Dorset. Master's dissertation, University of Cambridge.

College of Policing (2015). Authorised professional practice on domestic abuse. Retrieved 5 Nov 2015 from https:/www.app.college.police.uk/app-content/major-investigation-and-public-protection/domesticabuse/.

DASH (2009). Domestic Abuse, Stalking and Harassment and Honour Based Violence (DASH, 2009) risk identification and assessment and management model. Retrieved 26 Apr 2015 from http://www. dashriskchecklist.co.uk/index.php?page=dash-2009-model-for-practitioners.

Dorset County Council (2015). Pan Dorset MARACs operating protocol. Retrieved 24 Apr 2015 from http://www.dorsetforyou.com/marac.

Farrington, D., Coid, J., Harnett, L., Jolliffe, D., Soteriou, N., Turner, R., \& West, D. (2006). Criminal careers up to age 50 and life success up to age 48: new findings from the Cambridge Study in Delinquent Development Home Office Research Study 299. London: Home Office.

Her Majesty's Inspectorate of Constabulary (2014a). Everyone's business: improving police response to domestic abuse. Retrieved 24 Apr 2015 from http://www.hmic.gov.uk/publication/improving-thepolice-response-to-domestic-abuse/.

Her Majesty's Inspectorate of Constabulary (2014b). Dorset Police's approach to tackling domestic abuse. Retrieved 24 Apr 2015 from http:/www.hmic.gov.uk/publication/improving-the-police-response-todomestic-abuse/.

Home Office (2013). Circular 003/2013, Retrieved 30 Apr 2015 from https://www.gov. uk/government/publications/new-government-domestic-violence-and-abuse-definition.

Lewallen, S., \& Courtright, P. (1998). Epidemiology in practice: case-control studies. Community Eye Health, $11(28), 57-58$.

Monahan, J., \& Steadman, H. (2003). Crime and mental disorder: an epidemiological approach. In P. Bean (Ed.), Critical concepts in sociology. London: Routledge.

Schlesselman, J., \& Stolley, P. (1982). Case-control studies: design, conduct, analysis. Oxford: Oxford University Press.

Sherman, L. W. \& Strang, H. (1996). Policing domestic violence: the problem-solving paradigm. Paper presented at the Stockholm Conference on "Problem-Solving as Crime Prevention," Swedish National Council on Crime Prevention. http://aic.gov.au/media_library/aic/rjustice/rise/sherman-strang.pdf. 
Sherman, L. W., Schmidt, J. D., Rogan, D., \& DeRiso, C. (1990). Predicting domestic homicide: prior police contact and gun threats. Washington: Crime Control Institute.

Thornton, S. (2011). Predicting serious domestic assaults and murder in the Thames Valley. Master's dissertation, University of Cambridge.

Thornton, S. (2017). Predicting Domestic Murder and Serious Assaults in the Thames Valley. Cambridge Journal of Evidence-Based Policing 1. 